\title{
THE IMPACT OF CLINICAL LEADERSHIP ON QUALITY AND ACCREDITATION STUDIES IN HEALTH SERVICES
}

\author{
Elif Ozyurt ${ }^{1}$, Keziban Avci ${ }^{1,2}$, Figen Cizmeci Senel ${ }^{1}$
}

\author{
${ }^{1}$ Health Institutes of Turkey, Turkish Health Care Quality and Accreditation Institute, Ankara, Turkey \\ ${ }^{2}$ Ankara Yıldırım Beyazıt University, Ankara, Turkey
}

Address for Correspondence: Elif Ozyurt, E-mail: elifdoruk85@hotmail.com

Received: 22.06.2021; Accepted: 29.06.2021; Available Online Date: 20.08.2021

(C) Copyright 2021 by Dokuz Eylül University, Institute of Health Sciences - Available online at https://dergipark.org.tr/en/pub/jbachs

Cite this article as: Ozyurt E, Avci K, Cizmeci Senel F. The impact of clinical leadership on quality and accreditation studies in health services. J Basic Clin Health Sci 2021; 3: 221- 232.

\begin{abstract}
Purpose: The provision of a safe, high-quality, and standardised service in healthcare facilities requires the involvement and collaboration of various stakeholders. Trust and collaboration between stakeholders are a critical element for designing and implementing the measures needed in order to effectively monitor patient care outcomes. Successful implementation and evaluation of these measures requires clinical leadership practices based on collaboration and mutual respect among healthcare providers. In this study, it is aimed to discuss the effect of clinical leadership model on improving the quality of health services.

Methods: Based on the idea of minimising patient safety concerns in general, clinical leadership is defined as a shared and distributed leadership model in the delivery of health services. This type of leadership promotes a leadership understanding not based on formal authority, but which all health professionals can develop associatively rather than formally. It is also a practice developed to create reliable health facilities that take non-technical skills and the human factor into consideration and to provide health services in accordance with quality and accreditation standards.
\end{abstract}

Results: Especially in today's world where patient safety and quality of care are a source of concern, clinical leaders are at the forefront of ensuring the sustainability of quality and accreditation standards by guiding staff to continuously adopt and implement the quality improvement approaches.

Key Words: Clinical Leadership, Quality and Accreditation, Employee and Patient Safety,

\section{INTRODUCTION}

The search for improvement, change and innovative approaches in health services still continues although the quality of health services has improved significantly over time. Qualified health professionals are needed to make professional decisions about practices related to diagnosis, treatment and rehabilitation procedures that begin with the admission of patients to the hospital or clinic and to provide health care in accordance with evidencebased medical practices and in compliance with quality and accreditation standards. Being equipped with self-leadership and clinical governance skills is a necessity for health professionals (1). In other words, the changes and developments in the sector oblige health professionals to demonstrate clinical leadership.

Regardless of whether formally located in one of the administrative posts in the health facility's organisational chart, leadership is largely demanded of the clinicians who take an active role in the diagnostic, treatment and rehabilitation processes and are crucial in this regard. Health professionals 
are expected to provide a high quality and efficient service with a focus on patient and employee safety in the process of health service delivery (2). To the extent that they can integrate their expertise, management skills and leadership approaches, health professionals have a crucial role to play in improving quality and efficiency (3). Increasing demand for healthcare services, resource constraints, and rapid technological change and transformation due to factors such as the discovery of new diseases and increased life expectancy, as well as efforts to manage customer needs and expectations in this regard, highlight the importance of clinical leadership (4).

Providing a different perspective on the process of health service delivery than the traditional leadership approach, clinical leadership has brought about significant change. This change involves an understanding of leadership that stimulates the process of influencing others whom one is responsible for and supports both one's own personal development and that of the other team members who act with a team understanding in line with the organisational vision (5). From this point of view, clinical leaders change the behaviour of themselves as well as health professionals and patients in ways that increase both the level of health and the quality and efficiency of the service provided (6). Minimising changes and ensuring stable and standardised changes in health care is an important requisite for both reliability and the provision of a framework for professional excellence (5). In this regard, clinical leaders need to be well equipped, competent, and professional to maintain their own career development and make the decisions that are in the best interest of the health team, the healthcare provider, and the patients and reflect this in their practice (7). Clinical leaders are at the same time clinicians with skills to advocate for patients and affect the change (8). Taking all these requirements into account, the clinical leadership model is not a goal, project, or task on its own, but a tool for creating and sustaining high-performing health systems (9). As a guarantee of evidence-based health service delivery, clinical leadership practices are not just a modality that should be adopted by only a few clinicians, but by all clinicians $(10,11)$.

\section{CLINICAL LEADERSHIP AND ITS IMPORTANCE}

Today, healthcare organisations are facing pressures such as difficulties in attracting and retaining a skilled workforce, changing consumer expectations and demands, financial pressures, resource constraints, the obligation to improve patient-centred care and patient safety, and the willingness to deliver services in accordance with quality and accreditation standards (8). In addition, unintended patient outcomes, a culture of inappropriate care and the challenges associated with it, and the need for leadership at the clinical level are some of the facts that show that clinical leadership is needed to optimise patient care (12). Clinical leadership is particularly important in terms of efforts to provide diagnostic, treatment and rehabilitation services in health facilities at the highest level in the light of upto-date information with a safe, high-quality, efficient, and patient-centred understanding. This also requires clinicians to take a leadership role in the clinical setting to manage complexity in health care (8). The clinical leadership model, which is at the same time seen as focused on self-leadership and clinical governance, is crucial for the involvement and management of processes by the leaders whose necessity is highlighted in terms of quality improvement and accreditation in health care.

Based on the idea of minimising patient safety concerns in general, clinical leadership is defined as a shared and distributed leadership model in the delivery of health services. This type of leadership promotes a leadership understanding not based on formal authority, but which all health professionals can develop associatively rather than formally. It is also a practice developed to create reliable health facilities that take non-technical skills and the human factor into consideration and to provide health services in accordance with quality and accreditation standards (13).

As a member of the healthcare team, the clinical leader is competent to take responsibility for making decisions about clinical processes with a patientcentred perspective that focuses on trust, quality, sensitivity, and efficiency (14). The key leadership attributes a clinical leader should have are listed below. 
All health professionals in clinical services involved in the clinical care process are a clinical leader (15). Clinical Leader:

- $\quad$ is reachable by all stakeholders involved in the provision of services whenever they need the clinical leader.

- is distinguished by being directly involved in diagnostic and treatment processes.

- is competent in clinical knowledge and skills.

- behaves honestly to those he/she works with and is supportive and reassuring.

- possesses effective and strong interpersonal communication skills and can influence others.

- supports his/her teammates by acting as a mentor and role model.

- $\quad$ is a person with a vision and high conceptual skills who is rational and innovative as well as able to deal with uncertainty and foresee opportunities and threats (16).

- is value-driven and has a professional identity.

- influences the healthcare process with a critical approach to decisions/situations.

- $\quad$ holds the team together and empowers them to act with his/her integrative character.

- $\quad$ has got a high advocacy capacity (8).

- is responsive to the expectations of patients' relatives.

- guides members of the care team for evidencebased patient care.

- gives priority to effective and efficient use of resources.

- takes initiative and strives to maintain and raise standards and is motivated to implement the best practice.

- is the one who plans the order of priorities in the delivery of health service and ensures the optimal use of resources.

- $\quad$ is, together with other health professionals, a member of the team that complements each other and strengthens the other team members in a professional sense.

- taking institutional and social values and beliefs into account, encourages and ensures that members of the health team behave in accordance with these values in the process health services delivery (17).

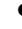

Clinical Leadership Development Process

Two UK reports called "Health for London: A Framework for Action, 2007" and "High Quality Care for All NHS Next Stage Review Report, 2008" addressed the importance of clinical leadership for high quality and safe health service delivery and suggested that health care providers, and in particular the National Health Services (NHS) Leadership Council, conduct studies on clinical leadership practices $(18,19,20)$. In this context, the NHS initially established a commission in 2010 consisting of 51 organisations representing the health sector and 97 competent experts. As a result of the studies conducted by this commission, physicians and nurses were divided into branches and "Clinical Leadership Competency Framework (CLCF))" was prepared at the clinical level under 21 titles, which includes the specialties of physicians and nurses $(21,22)$. According to the CLCF, not all clinicians need to be leaders, but everyone needs to contribute to the leadership process by practising the behaviours within the five key areas defined in the model.

\section{Clinical Leadership Competency Framework}

The CLCF defines the leadership competencies clinicians need in order to be more actively involved in the planning, delivery, improvement and development of health and social care services. It is applicable to every clinician at any stage of their professional life, from the moment they begin their professional training to the moment they become qualified as a practitioner, while they continue their ongoing professional development as a highly skilled clinician and experienced practitioner. All areas and elements of the clinical leadership competency framework are dynamic. The CLCF comprises students, clinicians in training, experienced health professionals, senior staff of health facilities, and academics. However, the implementation of the competencies in the model differs depending on the career stage of the clinician and the type of role the clinician fulfils. The level which competence can be acquired at can become more complex and demanding with the progress in professional life (15, 23, 24).

An important initiative to define the competencies which clinical leaders should apply for in order to support the leadership at all levels of clinical processes and to improve the quality of services for stakeholders, the CLCF has five domains $(23,25)$. 
1. Demonstrating Personal Qualities Area: This area can be considered as the clinician's heights, broadly.

1.1. Development of Self-Awareness: The value of clinicians is to be aware of their principles and upholdings.

1.2. Self-management: The ability to organize themselves, to manage their responsibilities, plans and their own planning.

1.3. Continuing Personal Development: It is an effort to correct one's own mistakes for personal gains and gains.

1.4. Acting Honestly: It is the application of open, honest and ethical principles.

2. Field of Work with Other Health Professionals: It refers to the development of skills to work with others within the health team and work networks in order to be successful.

2.1. Initiating and Improving Communication: It is an effort to identify and develop opportunities to benefit clinical processes with patients and all healthcare team members, and to seek the opinions of team members.

2.2. Building and Maintaining Relationships: Listening to and supporting others, gaining their trust, and building relationships with mutual understanding.

2.3. Encouraging Contribution: It includes encouraging and role modeling the entire healthcare team to make decisions and provide constructive feedback.

2.4. Working as a Team: It includes having goals and responsibilities as a team and respecting team members.

3. Area of Management of Services: It refers to focusing on the success of the health institution.

3.1. Planning: It includes planned work to achieve the goals, contributing to the planning process as an expert and getting feedback from all stakeholders in planning.

3.2. Resource Management: It is the identification of existing resources and the effective, efficient and effective use of resources.

3.3. Human Resources Management: It is the management of human resources consisting of features such as goal setting, motivating, performance evaluation and development.

3.4. Performance Management: It is taking action to increase performance by analyzing information about team performance and corporate performance.
4. Service Improvement Area: It includes the necessary motivation for high quality service delivery. 4.1. Ensuring Patient Safety: It covers high sensitivity for patient safety by managing risks for patients.

4.2. Critical Evaluation: It is to be able to produce solutions on where the service can be improved by thinking analytically and conceptually.

4.3. Encouraging Improvement and Innovation: Encouraging improvement and innovation by creating an environment that will make service delivery continuous.

4.4. Facilitating Transformation: Demonstrating leadership qualities by actively contributing to the improvement of processes and facilitating transformation.

5. Direction Setting Area: It includes contributing to the goals and strategies of the institution and acting in accordance with organizational values.

5.1. Determining the Content of Change: It is to follow new trends and expectations and to improve and develop clinical processes by being aware of the political, social, economic, technical, organizational and professional environment.

5.2. Using Information and Evidence: Gathering information and using evidence for evidence-based changes to systems and processes.

5.3. Decision Making: Making decisions using one's own values and available evidence to make sound decisions. This area also includes participating in and contributing to organizational decision-making processes.

5.4. Evaluation of the Impact: It covers the stages of measuring and evaluating the results, taking corrective actions when necessary, and reviewing their decisions.

The summary of the CLCF is shown in Figure 1 (adapted from 26) adapted from the NHS.

Clinical leadership practices are seen as an important element in developed countries to globally strengthen health systems and to develop health policies, however, relatively little work has been done in this regard in developing countries (27). The clinical leadership studies started in the UK and are gaining momentum notably in countries such as the USA, Australia, Canada, the Netherlands, and New Zealand $(21,22,28,29)$. 


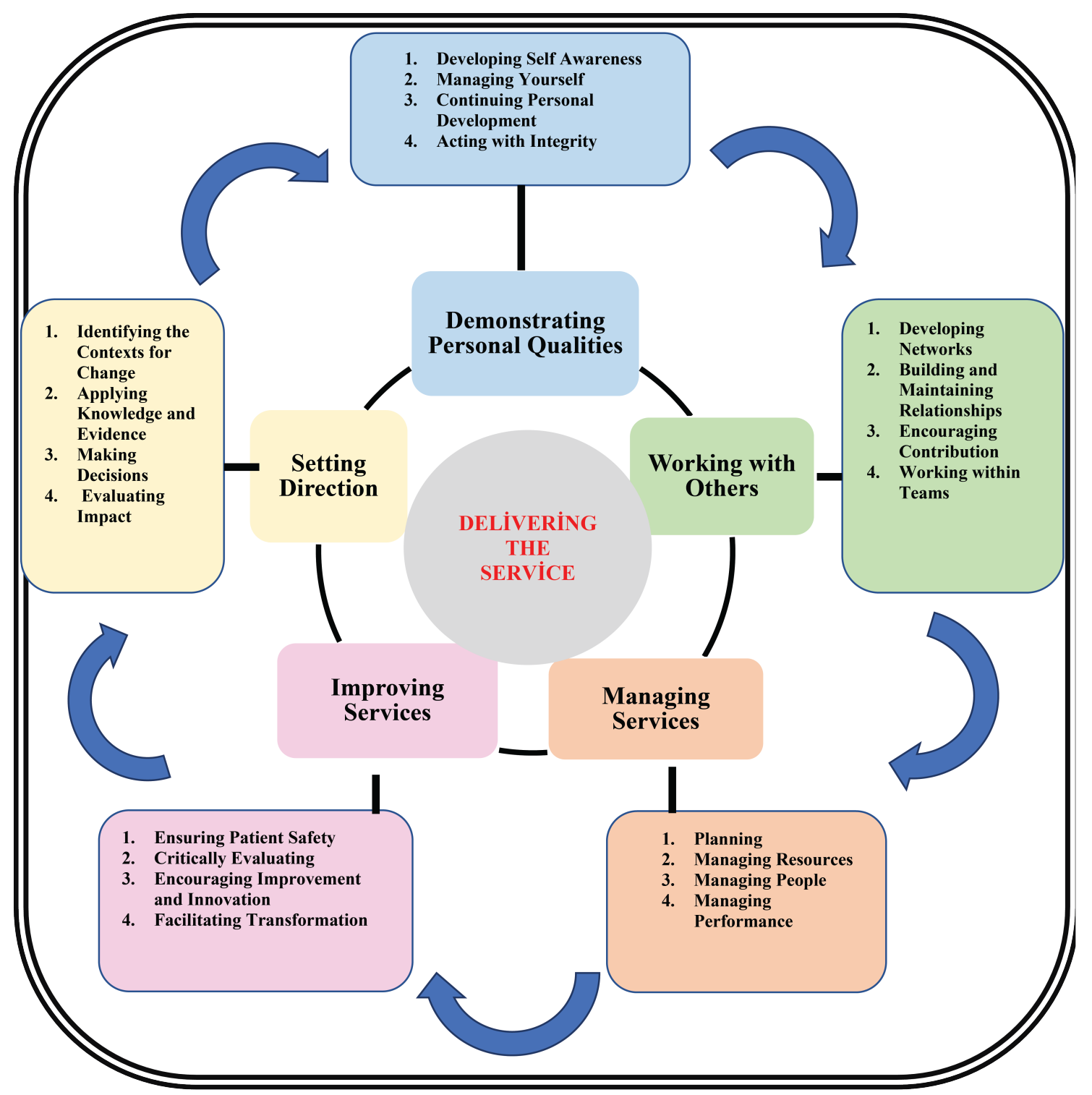

Figure 1. Clinical Leadership Competency Framework (adapted from 26)

\section{IMPACT OF CLINICAL LEADERSHIP PRACTICES ON THE HEALTH SYSTEM}

Health professionals trained in clinical leadership in health facilities are expected to make a difference in three critical areas: firstly, to improve collaboration and communication within the health team and between teams; secondly, to implement good practices in the health service delivery process; and thirdly, to initiate and effect change and transformation in the desired direction (30). A clinical leader is also expected to take responsibility and support the senior management for the tasks of the health facility and for the achievement of its goals. In this context, it is important that clinical leaders bring a different perspective to strategic decisions, both in senior management meetings and team meetings, so that decisions are made that are supported by employees (24). This study will discuss the impact of clinical leadership practices on the health system in terms of patients, the staff, and the operation of health facilities.

\section{Impact of Clinical Leadership Practices on Patient Diagnosis, Treatment and Rehabilitation}

The literature suggests that clinical leadership practices facilitate continuous care through multidisciplinary and coordinated team collaboration and improve patient outcomes by optimising 
diagnosis, treatment, and rehabilitation processes $(31,32,33,34,35)$.

The study by Jamiu et al. (2020) examining the impact of the clinical leadership programme on the pressure ulcer care process found that clinical leadership practices positively influenced the treatment planning and administration, as well as patient information processes, and strengthened multidisciplinary communication networks (36).

Arensberg et al. (2019) achieved successful outcomes for early diagnosis and treatment of malnutrition in patients with a long average admission time and high readmission by using the clinical leadership model and the Malnutrition Quality Improvement Initiative (MQii) tool (37).

Husebo and Olsen (2019), on the other hand, assessed the approach of the clinicians who did and did not receive clinical leadership training in the emergency department to the diagnostic and treatment processes of patients. According to this study, the healthcare professionals who received clinical leadership training assessed patients with team understanding and the team members complemented each other and met patients' expectations at the highest level, thus, great improvements were made in scheduling shifts, providing resources, providing and monitoring adequate patient flow, monitoring and ensuring information flow, ensuring patient care and treatment quality, and making treatment plans according to patients' health conditions and the informed consent (38).

The literature also suggests that clinical leadership practices facilitate patient access to diagnostic, treatment, and rehabilitation processes, improve patient satisfaction and waiting times and develop new services or service models in response to patient needs $(31,32,35)$. In Bridgman and McGrady's (2015) study which examined the impact of clinical leadership practices on primary dental health and care, it was observed that patient experience improved, satisfaction increased, and awareness of critical situations increased with clinical leadership practice (39). Similarly, the study by Begley et al. (2013) showed that clinical leadership contributed to optimising patient outcomes by establishing effective relationships in interdisciplinary teams and by training, guiding and leading teams (40).

\section{Impact of Clinical Leadership Practices on Employees}

The literature suggests that clinical leaders take on the role of a resource who trains, guides and coaches staff in interdisciplinary teams $(17,31,32,35,41)$, and serve as mentors for disciplines other than their branch $(17,32,33,34,40)$.

The study by Jamiu et al. (2020) investigated the views of the health professionals who participated in a clinical leadership programme on the impact of the programme on the health system. The programme participants made the following comments:

$\checkmark$ They acquired new information for their personal and professional development,

$\checkmark$ The hierarchy and gaps between different professional groups were reduced,

$\checkmark$ Interprofessional communication was strengthened,

$\checkmark$ Participation in active group training and the importance attached to information increased,

$\checkmark$ Institutional integration and the level of involvement of the team in defining and adopting strategies for a vision developed with this improved and their perspectives on the processes changed in a positive direction,

$\checkmark$ The motivation to tackle the previously ignored problems, to identify the causes and to look for solutions increased,

$\checkmark$ Employee welfare and patient and employee satisfaction would increase by putting what was learnt into application,

$\checkmark$ Participation in efforts to overcome patient expectations and to continuously improve diagnostic, treatment and rehabilitation processes increased (36).

A study by Hofmann and Vermunt (2021) showed that clinical leadership facilitated individuals to find new solutions to existing problems within their field by increasing collaboration between disciplines and professions (27).

Husebo and Olsen (2019) emphasised that those who worked in facilities with an evolving clinical leadership culture multitasked and became visionary, reliable, efficient, high-quality, and effective service 
providers by complementing each other as clinical leaders (38).

A study examining the effectiveness of clinical leadership training for internal medicine residents found that participants learnt different leadership styles, how to deal with conflicts and became aware of their strengths and weaknesses as leaders and increased their interest in advanced clinical leadership training (42).

The literature suggests a positive linear relationship between the clinical leadership performance and the occupational satisfaction, job satisfaction, job performance, loyalty to the institution and the job and productivity of the medical staff $(8,43,44,45,46)$. In this context, clinicians indicated that there was greater job satisfaction, increased personal satisfaction with their own performance and more opportunities for professional development in clinical leadership practices and that they took great pride in the performance of other team members $(47,48)$. Furthermore, Giles et al. (2018) underlined the collaborative role of clinical leaders in coordinating and managing complex cases transcending professional boundaries (17).

\section{Impact of Clinical Leadership Practices on the Operation of Health Care Facilities}

Clinical leadership is recognised as an important element in strengthening the global health system (49). The contribution of clinical leadership to safe and efficient health care is highlighted in government reports $(50,51)$.

The contribution of clinical leadership practices to the planning of health services, the updating of guidelines and protocols for the operation of health facilities and to organisational goals and outcomes are the key elements cited in the literature in this respect $(32,45$, 52). According to a study conducted in this context by Giles et al., there is a link between managerial decision-making and the impact of strategic initiatives at the clinical level (17).

Hofmann and Vermunt (2021) found that in facilities with an evolving clinical leadership culture, a culture of sharing developed, facilitating the dissemination of acquired knowledge among colleagues and professionals, and interest in initiatives and process improvement efforts increased (27).

In the study by Kakeman and Goodall (2019), which examined the performance of 72 hospitals in Tehran, directors with health knowledge, most of whom were physicians, were compared with directors without health knowledge. The study found that the performance scores of the hospitals led by managers with clinical training and experience were higher (53). To improve the quality of services, it was suggested that clinical leadership studies were needed in which top managers would actively involve clinicians and patients in the reform process (54). This is also necessary to improve the quality of healthcare services. As patient and employee safety, the quality of patient care and patient outcomes and satisfaction improve, service delivery improves and waste and medical errors in healthcare facilities are reduced, making business processes more efficient and creating a healthy practice and service environment (48).

\section{OBSTACLES TO THE DEVELOPMENT OF CLINICAL LEADERSHIP}

Although effective clinical leadership has been suggested as a useful tool for optimal, safe, and highquality service delivery and for addressing clinical problems, it is still difficult to establish a standard definition for clinical leadership $(55,56)$. For this reason, some studies stress the need for physicians to play a significant role in this process. Created with a sharing-based understanding, "clinical leadership" has been designed to meet the needs of all clinical staff. The literature in general emphasises that the concept of clinical leadership is a generic term, thus, can be applied to all clinical staff. The clinical leadership model prepared for health care does not fall within the specific domain of a professional group (55). Thus, all health professionals are potential candidates for clinical leadership (57). But a minority of health professionals emphasise their concerns that clinical leadership has begun to be monopolised by the medical profession (58).

There are certain obstacles to the development and diffusion of clinical leadership although the positive impact of effective clinical leadership on patient outcomes, hospital performance and the multidisciplinary team approach is widely recognised in the literature. These obstacles can be listed as follows: 
- Male-dominated society structure that prevents an active role of female leaders for clinical leadership,

- Complexity in bureaucratic processes in hospitals,

- Existing planning weaknesses at corporate level (5),

- Dominance of medical professionals within the interprofessional hierarchy (49),

- Lack of vision among senior staff,

- Resistance to innovation and change, and

- Poor teamwork.

David et al. (2017) noted that clinical leadership development was hindered by causes such as lack of time or high clinical expectations and client demands in a limited period, increasing bureaucracy, lack of clinical leadership opportunities, in other words lack of training opportunities, exhaustion and lack of mentoring and trust (60).

\section{DISCUSSION AND CONCLUSIONS}

The provision of a safe, high-quality, and standardised service in healthcare facilities requires the involvement and collaboration of various stakeholders. Trust and collaboration between stakeholders are a critical element for designing and implementing the measures needed in order to effectively monitor patient care outcomes (61). Successful implementation and evaluation of these measures requires clinical leadership practices based on collaboration and mutual respect among healthcare providers $(61,62)$. In addition, determining the skills and competency levels needed by health professionals and changing the cultural climate characteristics that prevent optimal performance require working within a system. In this respect, Clinical leadership is necessary to promote improving healthcare outcomes (62).

It is well known that management practices in healthcare facilities influence patient outcomes and institutional performance (63). In addition to good management practices, interest in the clinical leadership model is also growing every day along with the positive impact of clinical leadership on health systems. We can say that advanced innovative practices in health care (64) have improved quality and safety and are receiving increasing attention in this respect (45).
Clinical leaders in healthcare facilities contribute greatly to the healthcare system by focusing on the development of a culture of quality and safety, the implementation of innovative practices, the safety and quality of the working environment and the continuous improvement of the services provided. Especially in today's world where patient safety and quality of care are a source of concern, clinical leaders are at the forefront of ensuring the sustainability of quality and accreditation standards by guiding staff to continuously adopt and implement the quality improvement approaches $(65,66,67)$.

Ensuring patient safety in health services and eliminating risks, as well as achieving high quality and efficient health outcomes, requires the collaboration of the healthcare team. Successful collaboration requires empowering and upskilling healthcare providers and sharing leadership capacity and responsibilities among team members. Clinical leadership comes to the fore in this context and promotes teamwork and patient-centred care as well as shared leadership.

Clinical leadership is critical in making quick and accurate decisions regarding patient safety, particularly in areas where specialised services are provided such as accident and emergency units, intensive care units and operating theatres in healthcare facilities. By developing the clinical leadership skills of the clinicians working in such settings, services will be delivered easily, quickly, efficiently, reliably and with high quality within a team mentality.

Given the impact of clinical leadership on the health system and the growing interest in it, it is important to organise the training of health professionals at all levels, starting with basic training. In this regard, the Ministry of Health's initiative alongside the Council of Higher Education as a regulatory and supervisory body in health worker training, including lifelong learning, is a critical factor in the success of the process. Indeed, the Ministry of Health's 2019-2023 strategic plan states that the Health Institutes of Turkey will initiate work on clinical leadership training as part of the competency enhancing practices for health professionals. This initiative aimed at improving the self-leadership and clinical governance skills of health workers is promising, considering that 
the issue is systematically addressed in government plans (68).

Conflict of Interest: The authors report no conflict of interest. Peer-review: Externally peer-reviewed.

\section{REFERENCES}

1. Avcı E.Ö. ve Başer M., Klinik karar verme sürecinde Hemşirelerin Liderlik Özellikleri, Erciyes Üniversitesi Sağlık Bilimleri Fakültesi Dergisi, 2019; 6 (2):1-5.

2. McSherry, R., \& Pearce, P. what are the effective ways to translate clinical leadership into health care quality improvement? Journal of Healthcare Leadership, 2016; 8, 11,11-17.

3. Jeon, Y. H., Conway, J., Chenoweth, L., Weise, J., Thomas, T. H., \& Williams, A. Validation of a clinical leadership qualities framework for managers in aged care: a Delphi study. Journal of Clinical Nursing, 2015; 24(7-8), 999-1010.

4. Gün, İ., \& Aslan, Ö. Liderlik kuramları ve sağlık işletmelerinde liderlik. Journal of Health and Nursing Management, 2018; 5(3), 217-226.

5. Donald, D. U., Clinical Leadership as a Corollary for Professional Practice and Patient Safety, International Journal of Emergency Mental Health and Human Resilience, Vol. 17, No.1, pp. 2015; 262-266, ISSN 1522-4821

6. Lawrence, N. \& Richardson, J. To Explore and Understand the Leadership Experiences of Modern Matrons, Within an Acute NHS Trust. Journal of Nursing Management, 2014; 22(1), 7079.

7. West, M. Developing Collective Leadership for Health Care. The King's Fund, 2: London. 2014,http://www.kingsfund.org.uk/sites/files/kf/fie Id/field_publication_file/ engagement-improvement-nhs-finalreview2012.pdf. ISBN: 9781909029316

8. Daly, J., Jackson, D., Mannix, J., Davidson, P. M., \& Hutchinson, M. The importance of clinical leadership in the hospital setting. Journal of Healthcare Leadership, 2014; 6, 75-83.

9. Poddar, R. Learning between Managers and Doctors. British Journal of Healthcare Management; 2013; 19 (4): 192-197

10. Busari, J.O. Management and Leadership Development in Healthcare and The Challenges Facing Physician Managers in Clinical Practice. The International Journal of Clinical Leadership, 2013; 17(4), 211-216. Radcliffe Publishing Ltd.
11. Nath, V., \& Clark, J. Medical Engagement: A Journey, not an Event. London: The King's Fund. 2014, ISBN: 9781909029088

12. Garling P. Final Report of the Special Commission of Inquiry: Acute Care in NSW Public Hospitals, 2008 - Overview. Sydney, NSW: NSW Government; 2008., Available from: http://www.dpc.nsw.

gov.au/_data/assets/pdf_file/0003/34194/Overv iew__Special

Commission_Of_Inquiry_Into_Acute_Care_Servi ces_In_New_South_

Wales_Public_Hospitals.pdf. Accessed April 9, 2014.

13. Snelling, I., Brown, H., Hardy, L., Cockburn, S., and Somerset, L., An Evaluation Of The Health Education England South West Clinical Leadership Mentors Programme, NHS Health Education England, July 2020.

14. Olsen O, Husebo $S$, Qvindesland $S$, et al. Redefining clinical leadership for team course development. jhosp admin. 2015; 4: 52-60.

15. NHS, Clinical Leadership Competency Framework: Self Assessment Tool. NHS Leadership Academy: Leeds. 2012.

16. Stanley, D. Clinical leadership characteristics confirmed. Journal of Research in Nursing, 2014; 19, 118-128.

17. Giles, M., Parker, V., Conway, J., \& Mitchell, R. Knowing how to get things done. Nurse Consultants as Clinical Leaders. Journal of Clinical Nursing, 2018; 27(9-10), 19811993.https://doi.org/10.1111/jocn.14327

18. Darzi, A. Healthcare for London: A Framework for Action, London: NHS Reports, 4 October, 2007.

19. Department of Health, NHS Next Stage Review: A High Quality Workforce, London: NHS, 2008 a.

20. Department of Health, NHS Next Stage Review Final Report: High Quality Care For All, London: NHS, 2008 b.

21. NHS, Clinical Leadership Competency Framework Project: Report on Findings, London: National Leadership Council, 2010.

22. Budak. F. Sağlık Yönetiminde Klinik Liderlik, Klinik Liderlik ölçeği, Ankara: Siyasal Kitapevi; 2018, s: 63.

23. NHS Leadership Academy. Clinical leadership competency framework: NHS institute for innovation and improvement. Coventry: Coventry House University of Warwick campus, 2011. 
24. NHS, Clinical leadership a framework for action. NHS Improvement. IG 02/19 Erişim; 2019.https://improvement.nhs.uk/documents/37 02/Clinical_leadership_framework_Jan2019.pdf, 25.12.2020.

25. Özkan, Ş., Klinik Liderlik ve Sağlık Kurumlarına Yansımaları, Uluslararası Liderlik Çalışmaları Dergisi: Kuram ve Uygulama (International Journal of Leadership Studies: Theory and Practice) 2021; 4 (1), 40-50.

26. NHS, Clinical Leadership Competency Framework, Leadership Academy, 2011.

27. Jacinta Nzinga, Gerry McGivern and Mike English, Examining clinical leadership in Kenyan public hospitals through the distributed leadership lens, Health Policy and Planning, 33, 2018, ii27-ii34.

28. Gauld, R. ve Horsburgh, S., Clinical Governance Assessment Project: Final Report on a National Health Professional Survey and Site Visits to 19 New Zealand DHBs, Dunedin: Centre for Health Systems, University of Otago, 2012

29. VQC, (2005). Developing the Clinical Leadership Role in Clinical Governance: A Guide for Clinicians and Health Services, Victoria: Department of Human Services.

30. Hofmann, R., and Vermunt, J. D. Professional learning, organisational change and clinical leadership development outcomes. Medical Education, 2021; 55: 252-265.

31. Coyne, I., Comiskey, C. M., Lalor, J. G., Higgins, A., Elliott, N., \& Begley, C. An exploration of clinical practice in sites with and with-out clinical nurse or midwife specialists or advanced nurse practi-tioners, in Ireland. BMC Health Services Research, 2016; 16(1), 151.

32. Elliott, N., Higgins, A., Begley, C., Lalor, J., Sheerin, F., Coyne, I., \& Murphy, K.The identification of clinical and professional leadership activities of advanced practitioners: Findings from the Specialist Clinical and Advanced Practitioner Evaluation study in Ireland. Journal of Advanced Nursing, 2013; 69(5), 1037-1050.

33. Higgins, A., Begley, C., Lalor, J., Coyne, I., Murphy, K., \& Elliott, N. Factors influencing advanced practitioners' ability to enact leadership: A case study within Irish healthcare. Journal of Nursing Management, 2014; 22(7), 894-905.
34. Santiano, N., Young, L., Baramy, L.-S., McDonnell, S., Page, K., Cabrera, R., \& Chapman, A. How do CNCs construct their after hours support role in a major metropolitan hospital. Collegian (Royal College of Nursing, Australia), 2009; 16(2), 85-97.

35. Walsh, K., Bothe, J., Edgar, D., Beaven, G., Burgess, B., Dickson, V., Dunn, S., Horning, L., Jensen, J., Kandl, B., Nonu, M., Owen, F., \& Moss, C. Investigating the role of Clinical Nurse Consultants in one health district from multiple stakeholder perspectives: A cooper-ative inquiry. Contemporary Nurse, 2015; 51(2-3), 171-187. https://doi.org/10.1080/10376 178.2016.1169936

36. Jamiu O, Busari, Huriye Yaldiz, Reinold OB Gans ve Ashley J Duits, Clinical Leadership As An Agent For Change: A Health System Improvement Intervention İ Curaçao, Journal of Multidisciplinary Healthcare, 2020; 13, 787-798

37. Arensberg, M. B., D'Andrea, C., Khan, M., Clinical Leadership and Innovation Help Achieve Malnutrition Quality Improvement Initiative Success, by the Academy of Nutrition and Dietetics, 2019.

38. Husebø S. E., and Olsen, Q. E., Actual clinical leadership: a shadowing study of charge nurses and doctors on-call in the emergency department, Scandinavian Journal of Trauma, Resuscitation and Emergency Medicine 27, Article number: 2, 2019.

39. Bridgman C., McGrady M.G., Clinical leadership and prevention in practice: is a needs led preventive approach to the delivery of care to improve quality, outcomes and value in primary dental care practice a realistic concept? BMC Oral Health 2015; 15 (Suppl 1): S2.

40. Begley, C., Elliott, N., Lalor, J., Coyne, I., Higgins, A., \& Comiskey, C. M. Differences between clinical specialist and ad-vanced practitioner clinical practice, leadership, and research roles, responsibilities, and perceived outcomes (the SCAPE study). Journal of Advanced Nursing, 2013; 69(6), 1323-1337.

41. Van Boekholt TA, Duits AJ, Busari JO. Health care transformation in a resource-limited environment: exploring the determinants of a good climate for change. J Multidiscip Healthc, 2019; 12:173-182.

42. Blumenthal, D. M., Bernard, K., Fraser, T. N., Bohnen, J., Zeidman, J., and Stone, V. E. Implementing a pilot leadership course for 
internal medicine residents: design considerations, participant impressions, and lessons learned, BMC Medical Education 2014; 14:257 http://www.biomedcentral.com/1472$6920 / 14 / 257$

43. Boamah, S. Linking nurses' clinical leadership to patient care quality: The role of transformational leadership and workplace empowerment. Canadian Journal of Nursing Research, 2018; 50(1), 9-19.

44. Boamah, S. A., Laschinger, H. K. S., Wong, C., \& Clarke, S. Effect of transformational leadership on job satisfaction and patient safety outcomes. Nursing outlook, 2018; 66(2), 180-189.

45. Mianda, S., \& Voce, A. Developing and evaluating clinical lead-ership interventions for frontline healthcare providers: A review of the literature. BMC Health Services Research, 2018; 18(1), 747. https://doi.org/10.1186/s1291 3-0183561-4

46. Sarto, F., \& Veronesi, G. Clinical leadership and hospital performance: assessing the evidence base. BMC health services research, 2016; 16(2), 169.

47. Downey, M., Parslow, S., \& Smart, M. The hidden treasure in nursing leader- ship: Informal leaders. Journal of Nursing Management, 2011; 19 (4), 517-521.

48. George, V., Burke, L., Rodgers, B., Duthie, N., Hoffmann, M.L., Koceja, V., ... Gehring, L.L. Developing staff nurse shared leadership behavior in profes- sional nursing practice. Nursing Admini- stration Quarterly, 2002; 26(3), 44-59.

49. Nzinga, J., McGivern, G. and English, M., Examining clinical leadership in Kenyan public hospitals through the distributed leadership lens, Health Policy and Planning, 33, 2018; ii27-ii34 doi: 10.1093/heapol/czx167 Original Article

50. Keogh, B. Review into the quality of care and treatment provided by 14 hospital trusts in England: Overview report. Department of Health, 2013, Retrieved from https://www.nhs.uk/nhsen gland/ bruce -keogh -revie w/docum ents/outco mes/keogh -revie w-final -report. pdf

51. Kirkup, B. The Report of the Morecambe Bay Investigation: An in-dependent investigation into the management, delivery and outcomes of care provided by the maternity and neonatal services at the University Hospitals of Morecambe Bay
NHS Foundation Trust from January 2004 to June 2013, 2015.

52. Jonas, S., McCay, L., \& Keogh, B. The importance of clinical lead-ership. In $A B C$ of clinical leadership. Wiley-Blackwell, BMJ Books, 2011.

53. Kakemam, E. And Goodall, A.H., Hospital performance and clinical leadership: New evidence from Iran. BMJ Leader, 2019; doi: 10.1136/leader-2019-000160

54. Committee on Quality of Healthcare in America. Crossing the quality chasm. A new health system for the 21st century. Washington, DC: Institute of Medicine; 2001. Available from: http://www.iom.edu/ Reports/2001/Crossing-theQuality-Chasm-A-New-Health-System- for-the21st-Century.aspx. Accessed February 21, 2014.

55. Howieson $B$, and Thaigarajah $T$. What is clinical leadership? A journal- based meta-review. Int $\mathrm{J}$ Clin Leadersh. 2011; 17:7-18.

56. Mannix J, Wilkes L, Daly J. Attributes of clinical leadership in con- temporary nursing: an integrative review. Contemp Nurse. 2013; 45(1): 10-21.

57. Davidson P, Elliott D, Daly J. Clinical leadership in contemporary clinical practice: implications for nursing in Australia. J Nurs Manag. 2006;14(3):180-187.

58. Nicol, E.D., Mohanna, K. and Cowpe, J., Clinical Leadership Perspectives: A Qualitative Study Exploring the Views of Top Healthcare Leaders in the UK. Journal of the Royal Society of Medicine; 2014; Vol. 107(7) 277-286 doi: $10.1177 / 0141076814527274$

59. Martin J, McCormack B, Fitzsimons D, Spirig R. Evaluation of a clinical leadership programme for nurse leaders. J Nurs Manag. 2012; 20 (1):7280.

60. David Stanley, Denise Blanchard, Amali Hohol, Marani Hutton \& Anna McDonald (2017) To cite this article: Health professionals' perceptions of clinical leadership. A pilot study, Cogent Medicine, 4:1, 1321193.

61. Busari JO, Moll FM, Duits AJ. Understanding the impact of inter- professional collaboration on the quality of care: a case report from a small-scale resource limited health care environment. 10, 227. J Multidiscip Healthc. 2017; 10(227):227234.

62. Van Hecke, A., Goemaes, R., Verhaeghe, S., Beyers, W., Decoene, E., \& Beeckman, D. 
Leadership in nursing and midwifery: Activities and associated competencies of advanced practice nurses and mid-wives. Journal of Nursing Management, 2019; 27(6), 1261-1274.

63. Tsai, T. C., Jha, A. K., Gawande, A. A., Huckman, R. S., Bloom, N. \& Sadun, R. Hospital Board And Management Practices Are Strongly Related To Hospital Performance On Clinical Quality Metrics. Health Affairs, 2015; Vol. 34, No. 8, pp. 13041311.

64. Lamb, A., Martin-Misener, R., Bryant-Lukosius, D., \& Latimer, M. Describing the leadership capabilities of advanced practice nurses using a qualitative descriptive study. Nursing Open, 2018; 5(3), 400-413.

65. Collinson, D. Rethinking followership: a PostStructuralist Analysis of Follower Identities. The Leadership Quarterly, 2006; 17, 179-189.

66. Colla, C. H., Lewis, V. A., Shortell, S. M. \& Fisher, E. S. First National Survey Of Acos Finds That Clinicals Are Playing Strong Leadership And Ownership Roles. Health Affairs, Vol. 2014; 33, No. 6, pp. 964-971.

67. West, M. (2014). Developing Collective Leadership for Health Care. The King's Fund, 2:London.http://www.kingsfund.org.uk/ sites/ files/ kf/ field/ field publication file/ leadership-forengagement-improvement-nhs-finalreview2012.pdf. ISBN: 9781909029316.

68. Stratejik plan 2019-2023, Türkiye Sağlık Enstitüleri Başkanlığı. 